
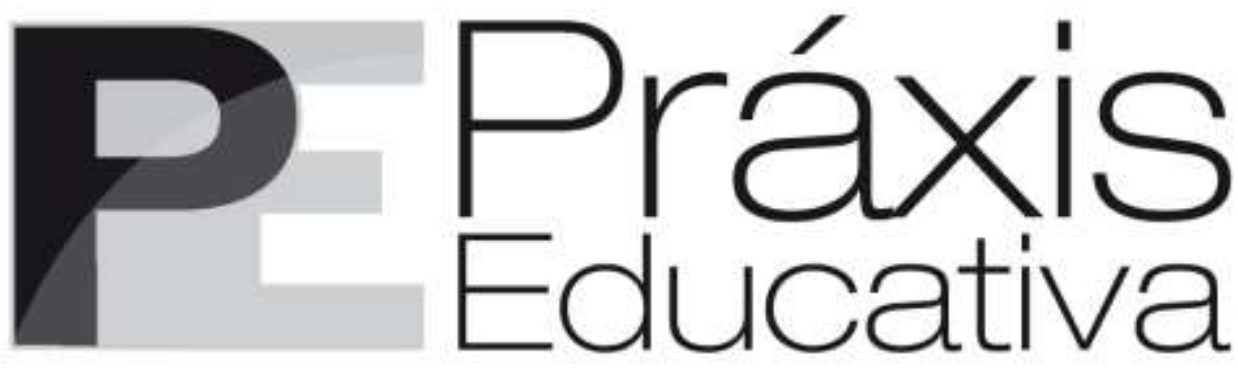

ISSN 1809-4031

eISSN 1809-4309

https://doi.org/10.5212/PraxEduc.v.17.19943.014

Seção: Tradução

\title{
O desafio da individualidade na Teoria da Atividade Histórico-Cultural: dialética "coletividual" a partir de um posicionamento ativista transformador ${ }^{*}$
}

\author{
The challenge of individuality in Cultural-Historical Activity Theory: \\ "collectividual" dialectics from a transformative activist stance
}

\section{El desafío de la individualidade en la Teoría de la Actividad Histórico- Cultural: dialéctica "colectividual" a partir de una postura activista transformadora}

\author{
Anna Stetsenko ** \\ iD https://orcid.org/0000-0003-0960-8875
}

\begin{abstract}
Resumo: Ao abordar o desafio persistente de integrar totalmente as dimensões individuais e a subjetividade humana dentro da Teoria da Atividade Histórico-Cultural, este artigo sugere várias etapas para revisar seu núcleo ontoepistemológico em uma abordagem expansiva denominada posicionamento ativista transformador. Essa abordagem delineia a dialética sutil dos planos individuais e coletivos da práxis humana, em que cada indivíduo é moldado pela história coletiva e por práticas colaborativas enquanto, ao mesmo
\end{abstract}

\footnotetext{
* Artigo inicialmente publicado em Outlines: Critical Practice Studies, v. 14, n. 2, p. 7-28, 2013. O artigo foi traduzido e publicado com a autorização do editor e da autora. Tradução de Janete Bridon. Revisão técnica de Jefferson Mainardes (UEPG). Financiamento: CNPq. Agradecemos ao editor Eduardo Vianna e Anna Stetsenko pela colaboração.

** Anna Stetsenko é Professora Titular do Programa de Doutorado em Psicologia, com nomeação conjunta no Programa de Doutoramento em Educação Urbana do The Graduate Center da City University de Nova Iorque (CUNY), EUA. Sua pesquisa está situada na interseção do desenvolvimento humano, da teoria social e da educação, incluindo tópicos de subjetividade, agência coletiva e pessoalidade vista através das lentes da mudança social. Antes de trabalhar nos Estados Unidos, ela trabalhou em universidades e centros de pesquisa na Rússia, na Alemanha, na Suíça e na Áustria. Suas publicações sobre o posicionamento ativista transformador se baseiam em avanços de ponta em filosofia e sociologia da prática, materialismo feminista e pós-modernista, teoria de sistemas dinâmicos, cognição situada e incorporada e estruturas de atividade histórico-cultural. Atualmente, ela está explorando implicações para o estudo da imaginação política, da ação coletiva e do ativismo. Ela está cada vez mais recorrendo à teoria social e política para interrogar as lacunas tradicionais, incluindo entre a agência individual e coletiva e entre a subjetividade e a ação social. E-mail: <astetsenko@gc.cuny.edu>.
}

Práxis Educativa, Ponta Grossa, v. 17, e2219943, p. 1-22, 2022 Disponível em: < https://revistas2.uepg.br/index.php/praxiseducativa> 
tempo, os molda e os percebe por meio da contribuição para sua materialidade coletiva e dinâmica, indo além do status quo. Ao capitalizar as pessoas sempre transcendendo o que existe no "aqui e agora", de forma não adaptativa, com base em um compromisso e visão de como o mundo "deveria ser", a subjetividade individual é reivindicada, em si própria, como um processo material-discursivo totalmente social e corporificado. A subjetividade individual e a agência ganham status ao contribuir para mudanças nas práticas "coletividual" como a ontoepistemologia primária de um domínio unitário que é ao mesmo tempo individual e social/coletivo.

Palavras-chave: Individual/social. Dialética. Práxis. Posicionamento ativista transformador.

\begin{abstract}
In addressing the persistent challenge of fully integrating individual dimensions and human subjectivity within the cultural-historical activity theory, this paper suggests several steps to revise its core onto-epistemology in an expansive approach termed the transformative activist stance. This approach outlines the subtle dialectics of individual and collective planes of human praxis whereby each individual is shaped by collective history and collaborative practices while at the same time shaping and realizing them through contributing to their collective, dynamic materiality in moving beyond the status quo. In capitalizing on people always transcending what exists in 'the here and now,' in a non-adaptive fashion, based in a commitment and vision to how the world "ought to be," the individual subjectivity is reclaimed as itself a fully social, embodied, material-discursive process. Individual subjectivity and agency gain status through contributing to changes in "collectividual" practices as the primary onto-epistemology of a unitary realm that is individual and social/collective at the same time.
\end{abstract}

Keywords: Individual/social. Dialectics. Praxis. Transformative Activist Stance.

Resumen: Al abordar el desafío persistente de integrar totalmente las dimensiones individuales y la subjetividad humana dentro de la Teoría de la Actividad Histórico-Cultural, este artículo sugiere varias etapas para revisar su núcleo ontoepistemológico en un enfoque expansivo denominado postura activista transformadora. Este enfoque delinea la sutil dialéctica de los planos individuales y colectivos de la praxis humana, en la que cada individuo es moldeado por la historia colectiva y por prácticas colaborativas mientras que, al mismo tiempo, los moldea y los percibe por medio de la contribución a su colectivo, para su materialidad colectiva y dinámica, yendo más allá del statu quo. Al capitalizar a las personas siempre trascendiendo lo que existen en el "aquí y ahora", de forma no adaptativa, con base en un compromiso y una visión de cómo "debería ser" el mundo, la subjetividad individual es reivindicada, en sí misma, como un proceso material-discursivo totalmente social y encorpado. La subjetividad individual y la agencia ganan estatus al contribuir a los cambios en las prácticas "colectividual" como la ontoepistemología primaria de un dominio unitario que es, al mismo tiempo, individual y social/colectivo.

Palabras clave: Individual/social. Dialéctica. Praxis. Postura ativista transformadora.

\title{
Introdução
}

A Teoria da Atividade Histórico-Cultural (TAHC) está atualmente desfrutando de muita popularidade e sucesso em uma variedade de campos e disciplinas que vão desde estudos organizacionais e de interações entre humanos e computadores até pesquisas sobre autorregulação, aquisição de segunda língua e alfabetização, entre muitos outros. Essa teoria lançou uma série de avanços teóricos (ainda não totalmente explorados) que estão em sintonia com as direções que agora estão liderando não menos do que uma revolução conceitual, como a teoria da dinâmica de sistemas, a abordagem de desenvolvimento de sistemas, a aprendizagem participativa, cognição incorporada, dinâmica, atuada e situada, epigenética do desenvolvimento, entre outros. Apesar de todas essas causas para celebração, é importante continuar a criticar e questionar de forma expansiva os princípios e as proposições básicas dessa teoria. As teorias são mantidas vivas revisitando continuamente e reconfigurando seus fundamentos no que pode ser chamado de "uma crítica de dentro" (STETSENKO, 1995) - um tipo de análise que visa a avançar, em vez de refutar, uma dada teoria por meio da elaboração de contradições dentro de suas zonas em constante

Práxis Educativa, Ponta Grossa, v. 17, e2219943, p. 1-22, 2022 Disponível em: < https://revistas2.uepg.br/index.php/praxiseducativa> 
evolução de desenvolvimento proximal que resultam de sua dinâmica dentro dos contextos sociais mutáveis dos quais participa (ver também LANGEMEYER, 2006). Parafraseando um ditado bem conhecido, pode-se dizer que se não houvesse controvérsias na TAHC, elas teriam de ser inventadas apenas para mantê-la viva. Essencialmente, é necessário autorreflexão para abordar possíveis riscos do emaranhado da TAHC com a dinâmica histórica-política, incluindo durante as recentes décadas tumultuadas, para evitar o risco de ficar cego em relação às questões de contexto, de poder e de mudança social.

Essa estratégia de interrogar criticamente, revisitar e reconfigurar amplas premissas teóricas da TAHC não significa afastar-se de investigações práticas e empíricas, mas, em vez disso, pode ser vista como uma parte inerente de tais investigações. O sucesso da TAHC sempre esteve associado ao profundo envolvimento de seus autores com questões teóricas e filosóficas e suas aplicações práticas mais notáveis que resultaram diretamente de tal envolvimento. Estes incluem programas de desenvolvimento para crianças com deficiência (trabalhos de Mesheryakov e Sokolyansky, para uma visão geral, ver BAKHURST; PADDEN, 1991) e programas educacionais (por exemplo, DAVYDOV, 1988, 1995; para uma visão geral, ver ARIEVITCH; STETSENKO, 2000). Não é por acaso que os autores desses programas educacionais estavam principalmente comprometidos com o desenvolvimento de conceituações filosóficas muito amplas do desenvolvimento humano. Por exemplo, as obras de Vassily V. Davydov foram marcadas por sua compreensão profunda do legado hegeliano-marxista e apoiadas por sua estreita colaboração com filósofos como E. V. Ilyenkov. Esses trabalhos funcionam como um exemplo direto de perceber o credo compartilhado por Vygotsky e outros fundadores da TAHC - a convicção sobre a natureza profundamente prática da teoria, a capacidade da teorização aparentemente abstrata para moldar e até mesmo determinar soluções para os problemas práticos primordiais, e em um nível mais profundo, sobre a inseparabilidade de dimensões teóricas e práticas de todas as atividades e todos os empreendimentos humanos.

Nesse espírito, eu empreendo uma revisão crítica de alguns dos fundamentos e das suposições no nível de visão de mundo da TAHC em suas implicações para a compreensão da subjetividade humana - com o objetivo de delinear contradições nessa abordagem que podem servir como pontos de crescimento para seus avanços e avanços futuros e desenvolvimentos. Essas contradições estão relacionadas às lacunas na definição do status ontológico da subjetividade humana, incluindo a mente e seus constituintes, como os conceitos e as tensões resultantes na integração total dos processos psicológicos e dos níveis individuais de atividade de forma mais ampla. É importante abordar essas tensões, especialmente devido ao atual clima sociopolítico de crise global aguda e rápidas mudanças sociais, a fim de fazer plena justiça às noções de transformação e de ativismo em função do desenvolvimento humano. Essas lacunas conceituais podem ser discernidas na abordagem de Davydov e na TAHC em geral, e, além disso (como ilustrarei nas seções a seguir), elas ainda repercutem na literatura e nas pesquisas atuais. Abordar essas controvérsias pode ajudar a desenvolver a TAHC de forma expansiva, de modo que seu poder explicativo e importância prática sejam fortalecidos ao reunir potenciais aliados que trabalham em direções próximas à TAHC, como a pedagogia crítica e a pesquisa-ação participativa, entre outros. Isso também pode ajudar a reparar algumas brechas que ocorreram dentro da TAHC, dividindo-a em direções de pesquisa um tanto distintas - dificilmente vantajosa para qualquer uma delas, especialmente dada a marcha implacável de abordagens alternativas, total e biologicamente reducionistas.

O argumento desenvolvido neste artigo é que é possível compreender a subjetividade humana enquanto permanece fiel aos principais dogmas e pressupostos dialéticos não dualistas. Isso pode ser feito se a subjetividade não é entendida como algum domínio inerentemente privado e auto-suficiente que é ontologicamente distinto de atividades colaborativas mundo a fora. A

Práxis Educativa, Ponta Grossa, v. 17, e2219943, p. 1-22, 2022 Disponível em: < https:// revistas2.uepg.br/index.php/praxiseducativa $>$ 
alternativa sugerida é explicar a subjetividade individual em termos de processos manifestos e inerentemente colaborativos de indivíduos agindo como sujeitos sociais (mesmo enquanto eles se engajam, como frequentemente o fazem, em suas próprias atividades aparentemente retraídas e privadas) - isto é, como membros de práticas comunitárias e agentes da história comunitária que representam (enact) coletividades, mudando-as por meio de suas próprias contribuições individualmente únicas, instanciadas em cada ato de saber, ser e fazer.

Nessa versão, a dificuldade em teorizar processos individuais, tradicionalmente denominados mentais, é integrada como uma tarefa legítima dentro do projeto geral de desenvolver uma visão totalmente dialética do desenvolvimento humano. Isso inclui conceptualizar a dialética sutil de planos individuais e coletivos da práxis humana pelos quais cada indivíduo - em todas as expressões, incluindo fenômenos psicológicos - é revelado ser constituído, incorporando, participando e, o mais importante, contribuindo para a materialidade dinâmica da história coletiva e das práticas colaborativas.

A tarefa crítica é compreender e explicar até mesmo os esforços aparentemente solipsistas, como processos de pensamento aparentemente individuais ou "internos" e formação de conceitos, dentro da estrutura não dualística, enquanto os revela como de fato nunca apenas solipsistas ou internos. Essa estratégia substitui teorias que, em vez de explicar os processos da subjetividade humana, de fato os justificam - como se qualquer consideração de seu status e desenvolvimento devesse implicar automaticamente um dualismo cartesiano. Em vez de resolver dualismos tradicionais simplesmente eliminando uma de suas partes constituintes, a abordagem sugerida aqui é empreendida no espírito de recuperar noções tradicionais, como conceitos individuais, e processos como internalização e autoria, que são deixados sob a alçada de abordagens desatualizadas que indevidamente os psicologizam, individualizam e mentalizam.

\section{O desafio da individualidade dentro da pesquisa da TAHC}

A marca registrada da TAHC é que ela considera a prática social, definida como atividade coletiva dirigida por objetivos humanos, como a base fundamental para o desenvolvimento e a aprendizagem humana e o faz por várias razões, incluindo aquelas derivadas da pesquisa em filogênese e ontogênese. Embora muitas teorias da prática tenham proliferado nas Ciências Sociais criando raízes em diversas fontes (como, além de Marx, as filosofias de Max Weber, Heidegger e Wittgenstein, ver, por exemplo, Bourdieu, Giddens, Foucault, Garfinkel, e outros), as obras de Vygotsky (1997, 1998a, 1998b, por exemplo,) e sua escola continuam a ser o verdadeiro grampo dessa abordagem, dando continuidade ao legado da filosofia marxista e merecendo status de uma perspectiva pioneira (cf. LANGEMEYER, 2006). De acordo com essa abordagem, os humanos passam a ser e a conhecer - uns aos outros, a si próprios e ao mundo - enquanto atuam conjuntamente práticas coletivas mediadas por ferramentas culturais (começando com as ferramentas de trabalho, até sistemas simbólicos complexos como a linguagem), com base nos esforços de cada um e nas conquistas das gerações anteriores, ao mesmo tempo em que expandem e amplificam cumulativamente essas conquistas. A atividade humana - material, prática e sempre por necessidade social, processos coletivos dependentes e mediados por ferramentas culturais - é vista, portanto, como a forma básica da vida social humana que é formativa de tudo o que é humano em humanos, incluindo sua subjetividade e suas formas como a mente, o conhecimento, os conceitos e a pessoalidade. Esses fenômenos subjetivos (psicológicos) são entendidos como relacionados a práticas/atividades colaborativas humanas e que evoluem no meio delas.

Uma das elaborações mais significativas dessa teoria, como já mencionado, foram os trabalhos de Vassily V. Davydov (1988, 1995, por exemplo), que merecem um escrutínio crítico

Práxis Educativa, Ponta Grossa, v. 17, e2219943, p. 1-22, 2022

Disponível em: < https://revistas2.uepg.br/index.php/praxiseducativa $>$ 
precisamente por causa de seus pontos fortes. Na teoria da atividade contínua, Davydov manteve que, nos atos de trabalho, as pessoas se movimentam além do imediatismo " natural" do mundo e, em vez disso, discernem eventos e objetos em suas inter-relações que são críticas para práticas coletivas humanas e que, de outra forma, permanecem ocultas. É porque as pessoas se envolvem em transformações práticas de seu mundo e acumulam suas experiências e descobertas através de gerações, em formas de prática universal da humanidade como um todo, que as relações sistêmicas entre fenômenos e processos gradualmente se revelam e são refletidas em conceitos. A prática coletiva da humanidade - tanto social em suas raízes genéticas quanto em seus métodos - foi, então, posta como o fundamento que dá origem ao pensamento incluindo suas formas teóricas que apreendem a realidade em seu essencial, isto é, abstraem ainda, ao mesmo tempo, características práticas (um ponto que será discutido com mais detalhes na última seção deste artigo).

No entanto, em termos de especificações ontológicas de como os processos psicológicos existem, Davydov (1988) parece reconhecer (ao seguir Ilyenkov) dois domínios, ou dois modos de existência - o de fenômenos ideais de natureza coletiva que incorporam descobertas colaborativas da humanidade, e a de conceitos individuais desenvolvidos quando as pessoas adquirem conceitos coletivos. A ligação entre esses dois domínios, de acordo com Davydov, consiste em indivíduos adquirindo formas culturais de conhecimento como ferramentas de práticas sócio-históricas que estão "por trás" de cada conceito. Esse processo de aquisição de conhecimento cultural foi postulado para ocorrer dentro das atividades práticas, culturalmente mediadas e socialmente situadas. Contudo, a relação entre a atividade material e os processos psicológicos foi ainda mais especificada, infelizmente, apenas afirmando que os dois estão de alguma forma interligados, mas sem muita exploração sobre como exatamente isso é possível e como os dois domínios são ontologicamente compatíveis. Sem tal especificação, não é de se admirar que os processos mentais tenham se tornado essencialmente equacionados com o processo de reflexão tradicionalmente entendido (otraz̧henie [Russo]) que, embora postulado como decorrente e existente no contexto da atividade, não é, porém, muito diferente da conotação de uma exibição interna de imagens na consciência individual. $O$ primeiro passo no desenvolvimento da mente, por exemplo, foi visto por Davydov (1988) como a formação de representações, em que uma imagem sensual de uma classe de objetos é separada dentro da atividade prática dos próprios objetos devido ao trabalho de imaginação (voobrą̧henie - russo), com essas imagens então generalizadas por meios linguísticos. Essa solução analítica, no entanto, deixou muitas lacunas, especialmente porque não desafiou as noções tradicionais de que os processos psicológicos servem para "refletir" a realidade. A velha conotação mental, apesar de desafiada por um foco em processos psicológicos originados de atividades práticas, sua confiança em ferramentas culturais e sua incorporação em atividades situadas, foi mantida de maneiras significativas.

Tensões e lacunas semelhantes continuaram em trabalhos posteriores afiliados às abordagens de Vygotsky e da teoria da atividade (por exemplo, ver STETSENKO, 1995). Como não há espaço para revisar todas as formas que essas tensões e lacunas assumiram ao longo dos anos, é útil recorrer a ilustrações de um capítulo recente de Vladislav A. Lektorsky (2009), a maior autoridade nesse campo na Rússia dos dias atuais. Em sua visão geral bem informada e cuidadosa das tendências e dos debates recentes em Filosofia e Psicologia, Lektorsky reproduz essencialmente a visão dupla que tipificou a abordagem original da TAHC. Admitindo que a oposição entre os mundos "interno" e "externo", entre o "imediatamente dado" e os fenômenos mediados, continua a ser um problema, Lektorsky passa a apresentar sua interpretação da teoria da atividade:

Do ponto de vista da teoria da atividade, a consciência e "o interior" são construções sociais e culturais e existem antes de tudo em formas de atividade coletiva. [...]. O sujeito como a unidade de consciência, a unidade de uma biografia individual e o centro da tomada de decisões pode existir apenas como o centro do "mundo interior". Entretanto, a aparência do "mundo interior" só é possível quando a ideia do "interior" surge em cultura, em outras palavras, quando é realizada em formas de atividade coletiva.

Práxis Educativa, Ponta Grossa, v. 17, e2219943, p. 1-22, 2022 Disponível em: < https://revistas2.uepg.br/index.php/praxiseducativa $>$ 
(LEKTORSKY, 2009, p. 80, tradução nossa) [...]. O sentimento "nós“ existe apenas nas mentes dos sujeitos individuais, participando de um certo tipo de atividade. (LEKTORSKY, 2009, p. 82, tradução nossa). Na realidade, o "espaço interior" da consciência é o resultado da apropriação individual de certos tipos de atividade coletiva externa. Portanto, podemos dizer que o tão chamado espaço interior existe primeiro nas ações exteriores, ações externas como parte da atividade coletiva. A internalização é impossível sem a participação em atividades externas mediadas. (LEKTORSKY, 2009, p. 83, tradução nossa).

Esse relato reafirma essencialmente o princípio central (e o agora "clássico" ou canônico, cf. SAWCHUK; STETSENKO, 2008) da TAHC de que a consciência humana é o resultado de indivíduos se apropriando da atividade coletiva externa no curso de sua participação e que o espaço interior existe primeiro na atividade coletiva exterior. Essa posição não se muda para além dos insights dos primeiros trabalhos de teóricos da atividade (certamente progressista para o seu tempo do início aos meados do século XX) e, de fato, deixa os mesmos enigmas não resolvidos, que é especialmente lamentável, dado que muitas décadas se passaram desde a concepção dessa teoria. Essa posição, para reiterar, não teoriza, nem demonstra, com quaisquer pormenores, como conciliar o "espaço interior" (o domínio psicológico) com a noção de atividades coletivas, deixando seu estado ontológico ambíguo e incerto.

\section{Posicionamento ativista transformador ${ }^{1}$}

Várias etapas para resolver os problemas difíceis descritos na seção anterior foram sugeridos no que denominei de posicionamento ativista transformador. Para recapitular a lógica dessa abordagem, meus esforços têm se focado, em primeiro lugar, em explicar o fundamento geral marxista, embora, em uma forma nascente, no centro das abordagens de Vygotsky e de seus seguidores imediatos, além de revelar diferenças entre seus respectivos focos - em contradição às posições (por exemplo, Kozulin, van der Ver e Valsiner) que separam os trabalhos desses acadêmicos em direções de pesquisa independentes e até mesmo contraditórias (para mais detalhes, ver STETSENKO, 2004; STETSENKO; ARIVITCH, 2004a). A exposição do fundamento geral presente nos trabalhos dos fundadores da teoria da atividade, e as diferenças entre suas posições (muitas vezes obscurecidas por interpretações que se concentram em tópicos mais específicos, como a mediação cultural), é apresentada como a dialética tripla das práticas sociais humanas (ver STETSENKO, 2005; para mais explicações, ver SAWCHUK; STETSENKO, 2008). Revela-se que essa dialética é composta pelas três camadas ou dimensões seguintes - os processos práticos de produzir materialmente condições de existência que dependem do emprego de ferramentas (isto é, trabalho humano); os processos intersubjetivos de comunicação social que organizam, estruturam e coordenam esses processos práticos; e os processos de subjetividade humana, incluindo a cognição, o eu e a agência, que permitem que os indivíduos sejam participantes plenos

\footnotetext{
${ }^{1}$ Nota de revisão: A respeito do Posicionamento Ativista Transformador, em Língua Portugesa, ver:

STETSENKO, A. Ético-ontoepistemologia ativista: pesquisa e estudo de resistência. In: ANPEd. Ética e pesquisa em educação: subsídios. v. 2. Rio de Janeiro: ANPEd, 2021. p. 1-9.
}

VIANNA, E.; STETSENKO, A. Compromisso e posicionamento: ética em pesquisa ativista transformadora. In: ANPEd. Associação Nacional de Pós-Graduação e Pesquisa em Educação. Ética e pesquisa em educação: subsídios. v. 2. Rio de Janeiro: ANPEd, 2021. p. 23-28.

MAINARDES, J. Autoentrevista. In: MAINARDES, J. Alfabetização \& prática pedagógica: trajetórias \& vivências. Curitiba: CRV, 2021. p. 127-143. https://www.researchgate.net/publication/353852233_ALFABETIZACAO_E_PRATICA_PEDAGOGICA_trajet orias_vivencias

Práxis Educativa, Ponta Grossa, v. 17, e2219943, p. 1-22, 2022 Disponível em: < https://revistas2.uepg.br/index.php/praxiseducativa $>$ 
nos processos de produzirem materialmente suas vidas, enquanto interagem socialmente e fazem intercâmbio com os outros. Essas três camadas ou dimensões são posicionadas como todas pertencentes, e juntas compreendem, a um domínio unificado e dinâmico de práticas sociais - o sistema complexo de praxis colaborativa bumana (STETSENKO, 2005).

Uma especificação adicional (STETSENKO, 2008, 2010a, 2012, 2013) consiste em expandir e acentuar esse fundamento geral, unificando os trabalhos dos fundadores da TAHC, por meio do destaque do status ontológico da práxis colaborativa como o domínio principal (ou o "tecido") da vida humana e do desenvolvimento, incluindo seus aspectos inter-relacionados de conhecer, ser e tornar-se. Essa especificação coloca ênfase na primazia ontológica da práxis colaborativa como um modo de vida ou existência (Lebensweise [alemão]; способ существования [russo]) única dos humanos que constituem o fundamento para o seu desenvolvimento em todas as suas expressões, dimensões e facetas, incluindo fenômenos do eu, da mente e da cognição. Uma importante estratégia analítica utilizada na colocação dessa posição - na preparação do próximo passo para o posicionamento ativista transformador - consiste em abordar como a TAHC é de fato construída em premissas totalmente relacionais e situadas em um reconhecimento de que as pessoas estão inextricavelmente incorporadas em seu mundo e constituídas pelas relações com ela, incluindo relações com outras pessoas e toda a humanidade. Isso permite uma comparação significativa da TAHC com abordagens igualmente relacionais que postulam interações e laços sociais, às vezes entendidas como dialogicalidade ou discurso, no núcleo do desenvolvimento. Por exemplo, de acordo com a explicação recente de Marková (2012),

[...] interdependência entre as mentes, em vez de seu isolamento, está profundamente enraizada na natureza humana e permeia todas as faculdades fundamentais como conhecer, adquirir conhecimento e crer, imaginar, sentir e agir. A socialidade é tão básica que define a existência humana: podemos chamá-la de ontologia dialógica. (MARKOVÁ, 2012, p. 211, grifo nosso, tradução nossa).

Minha sugestão tem sido reconhecer que essa perspectiva dialógica é compatível com a TAHC em um, embora nem todos (!), nível conceitual na teorização de desenvolvimento humano e práticas sociais. Como os seres humanos vêm a ser e se desenvolvem com e por meio de dinâmicas de seu modo de vida que os relacionam com seu mundo, incluindo outras pessoas, a principal ontologia do desenvolvimento é de fato totalmente relacional e dialógica. O que o posicionamento ativista transformador destaca em outro nível, no entanto, na continuação do legado de Vygotsky e de Leontiev, é que a ontologia dialógica e outras ontologias relacionais, como aquelas que priorizam discursos, experiências e participação, são substituídas por uma (indivisível, embora não homogênea) ontologia de práxis colaborativa unificada em sua materialidade e historicidade. É uma materialidade, coletividade e historicidade explícita das práticas colaborativas humanas que as tornam mais adequadas ao status de ontoepistemologia originária e primária do que a ontologia dialógica. A atuação incorporada da vida social em e por meio de atividades práticas colaborativas e ininterruptas da humanidade que se desdobram na história é ontológica e epistemologicamente primária e suprema em face às relações dialógicas, aos discursos e às experiências - essencialmente substituindo-os. $\mathrm{O}$ termo "substituindo", usado em sentido dialético, denota um movimento conceitual que não elimina um determinado fenômeno ou suas propriedades, mas, em vez disso, os eleva e os inclui, embora em um papel subordinado, em um novo todo sistêmico compreendido, neste caso, por práticas colaborativas humanas. Em outras palavras, essas práticas são totalmente dialógicas e relacionais, porém o que as torna o que são, sua característica e caráter formativo não podem ser reduzidos apenas à dialogicidade. Em vez disso, sua função formativa tem a ver com pessoas coletiva e materialmente produzindo as condições de sua existência, enquanto, ao longo do caminho, necessariamente interagem, dialogam, se relacionam, assim como vêm a desenvolver especificamente processos psicológicos humanos, agenciamento e subjetividade.

Práxis Educativa, Ponta Grossa, v. 17, e2219943, p. 1-22, 2022 
Minha outra sugestão, e mais crítica, tem sido enfatizar a natureza transformadora das práticas colaborativas, em seu status de principal ontoepistemologia do desenvolvimento humano, como sua função formativa chave, integrando, assim, mais explicitamente, as noções de mudança social e ativismo na descrições mais básicas da própria realidade do desenvolvimento humano e da dinâmica social. A ontologia transformadora da práxis humana resultante sugere que é diretamente por meio de e no processo (em vez de além de) de pessoas constantemente transformando e criando seu mundo social $\mathrm{e}$, assim, indo além do status quo que as pessoas simultaneamente criam e constantemente transformam sua própria vida, portanto também se modificam de maneiras fundamentais, enquanto, no processo, tornam-se individualmente únicas e ganham conhecimento sobre si e sobre o mundo. Embora o tema das pessoas que transformam seu mundo e são transformadas por ele é comum a muitos trabalhos com base nas práticas sociais de Vygotsky e em outros marxistas, seu significado ontológico e epistemológico e implicações profundas para praticamente todos os aspectos em explicar a vida social e o desenvolvimento humano não foram totalmente explorados, nem suficientemente absorvidos, muitas vezes resultando nessa premissa radical sendo acoplada a ideias e a pontos de vista antiquados.

A importância analítica de tomar a mudança social transformadora como a característica central das práticas sociais humanas, sugerida pela primeira vez (embora não totalmente explicada) por Marx, é, na verdade, enorme, implicando uma mudança conceitual na teorização do desenvolvimento humano e da sociedade que não é menos radical do que a importância da revolução de Darwin nas Ciências Biológicas (ver STETSENKO, 2010a, 2011). Enquanto Darwin introduziu a noção de mudança no que tinha sido um pensamento estático sobre a natureza como fixa e inerte, a inovação filosófico-conceitual marxista consistiu em derrubar modos tradicionais e igualmente estáticos de pensar, não apenas sobre a natureza, mas também sobre o desenvolvimento humano e a sociedade.

Em que se baseavam esses modos tradicionais de pensar sobre a sociedade e o desenvolvimento humano tacitamente durante a época de Darwin e Marx e no que continuam a se basear hoje é a suposição sobre a superioridade do status quo sociopolítico e cultural presente em um dado tempo e lugar como um "dado" de alguma forma estático e fixo, imutável e invariável que pode ser subestimado como uma reificação essencialista. Similarmente ao insight darwiniano, mas também indo além dele, a mudança conceitual e analítica implícita pela ontoepistemologia transformativa pressupõe uma espécie de "mindquake" [tremor mental] - uma mudança profunda no modo habitual de pensar por meio da qual os processos, tais como práticas sociais e seus produtos, não são reificados em nenhuma etapa analítica de suas descrições e análises. Em vez disso, o próprio modo de existência das práticas sociais e seus produtos é considerado como sendo caracterizado pela dinâmica de estar sempre em mudança e em movimento, continuamente reestruturando e reorganizando o movimento $e$ o fluxo de mudanças, transformações, transmutações e reestruturações incessantes. Nessa perspectiva, as mudanças e as transformações na práxis social comunitária é o que existe e o que substitui o mundo em sua fixidez e "realidade como algo dado" [givenness]. A mudança, em outras palavras, é ontologicamente primária, ao passo que a estabilidade e as formas, as estruturas e os padrões estáticos são derivados do que é a realidade primária composta de mudanças e de transformações onipresentes e incessantes na práxis comunitária dinâmica e sempre em desenvolvimento. Essa é uma mudança radical dos ideais atuais da ciência que ainda são baseados em ontologias de substâncias essencialistas, mantendo a variação e a mudança como anomalias a serem eliminadas na compreensão de algumas essências presumivelmente estáticas e suas "leis universais" a-históricas.

Em minha interpretação, é a simultaneidade e a unidade da prática transformativa humana, por um lado, e o processo de conhecer e tornar-se, por outro, que precisam ser tratados de forma mais central. Talvez a implicação mais marcante seja a ênfase na natureza não adaptativa do 
desenvolvimento humano como sempre indo além do "dado", sempre transcendendo o status quo do mundo como ele existe no "aqui e agora". Ou seja, saber, ser e fazer são entendidos como ontologicamente determinados por (embora não reduzidos a) atos de transformação que contribuem para a práxis social comunitária na conotação de criar novidade e ir além do dado para transcender seu status quo. Essa posição contrasta com as explicações "situacionistas" e "contextualistas" focadas no desenvolvimento como um processo passivo de pessoas situadas em seu contexto ou ambiente (como aquilo que simplesmente as cerca), isto é, como meramente habitando, ou experimentando, o mundo como na metáfora de "estar lá" (ver CLARK, 1997) e muitos trabalhos em teorias de cognição distribuídas, socioculturais e situadas, incluindo aquelas que seguem a noção heideggeriana de Dasein.

O ponto que a ontoepistemologia transformadora traz é que o desenvolvimento não é um processo que, de alguma forma, acontece às pessoas para que elas possam e às vezes também transformem as condições de sua existência, por exemplo, por meio de esforços supostamente suplementares que são realizados além do desenvolvimento. Em vez disso, a implicação radical da ontoepistemologia transformadora é que é no processo e como o processo de instigar mudanças nas práticas sociais que ocorre o desenvolvimento humano, pelo qual essas mudanças constituem a realidade central do desenvolvimento, as coisas (ou o tecido) a partir do qual o desenvolvimento é feito. Essa interpretação da dialética materialista marxista que permeia os trabalhos dentro da tradição fundadora da TAHC (embora implicitamente) enfatiza que as práticas sociais e os sistemas de atividade referem-se não apenas a fazer certas coisas para obter resultados específicos, mas a criar novas formas de realidade por meio do processo de reenquadrar e reconstruir atividades e estruturas sociais em andamento e, portanto, ir além delas em atos criativos de fazer, ser e saber. Esses atos criativos (como todos os atos humanos essencialmente são) não ocorrem apenas no mundo como na noção de cognição e desenvolvimento situada e incorporada; mas, sim, esses atos de ser, conhecer e fazer traz̧em à tona o mundo, a própria realidade, essencialmente criando o mundo em seu contínuo devir e historicidade.

É importante ressaltar que o próprio mundo social é subentendido no posicionamento ativista transformador como constituído por e por meio de práticas sociais transformadoras encenadas e realizadas por indivíduos agindo colaborativamente como sujeitos sociais - assim enfatizando, também, as transformações e as mudanças na realidade imediatamente presente como sua ontologia central, em vez dessa realidade ser um "dado" metafísico que existe independentemente da práxis social em sua atuação pelas pessoas e, portanto, independentemente da presença humana (como foi frequentemente assumido no marxismo "canônico" e, por extensão, nas obras fundadoras dos estudiosos da TAHC). Em outras palavras, o mundo é entendido como estando sempre em processo de mudança, como um terreno em constante mudança e movimento onde não há entidades separadas, mas um fluxo contínuo de processos em constante mudança. Além disso, por ser composto de atos e de feitos humanos, o mundo pode ser conceituado como um fórum coletivo de atos humanos mutáveis e em movimento. Em outras palavras, o mundo é entendido em sua relevância bumana - como um fluxo dinâmico e ininterrupto de práticas sociais acionáveis realizadas na forma de ações humanas que se estendem ao longo do tempo, compreendendo, assim, efetivamente a história como um continuum trazido à existência e encenado pelas pessoas. Assim entendido, o mundo não existe separadamente dos seres humanos e não pode ser descrito separadamente deles, isolado do que as pessoas realmente fazem e realizam em suas vidas, com as ações humanas constituindo nada menos que o próprio mundo vivido (BAKHTIN, 1990, 1993; ver STETSENKO, 2007). No centro do palco, eliminando a polaridade do ser humano e do mundo, está um processo unificado de pessoas transformando suas circunstâncias de vida e, simultaneamente, nesse mesmo processo, sendo transformadas por suas próprias práticas transformadoras. Esse movimento conceitual leva em conta que a pura ideia da realidade como algo dado ("givenness") é substituída pela imposição de uma atividade humana intencional que é composta da dinâmica em constante mudança de esforços e lutas transformadoras. Portanto, o próprio mundo, uma vez que é entendido como sendo feito de e por práticas transformadoras

Práxis Educativa, Ponta Grossa, v. 17, e2219943, p. 1-22, 2022 Disponível em: < https:// revistas2.uepg.br/index.php/praxiseducativa $>$ 
colaborativas, precisa e pode ser colocado como um domínio único, especificamente humano, inerentemente imbuído, bem no seu âmago, com dimensões humanas como relacionalidade, significado social, significados, esforços, lutas e valores.

Em um movimento conceitual relacionado, o posicionamento ativista transformador destaca a noção de que os indivíduos contribuem para práticas transformadoras colaborativas (em contraste com uma expansão dialética da noção de participação) por meio de seus próprios atos únicos e sua coautoria de práticas sociais historicamente reveladoras. Nesse sentido, as práticas colaborativas são postuladas como ontologicamente primárias, embora sejam entendidas como evoluindo contínua e cumulativamente por meio de contribuições ativistas únicas de participantes individuais, que sempre agem como sujeitos sociais e sempre importam de uma forma ou de outra porque estão diretamente implicados na criação de suas realidades de existência e de seu desenvolvimento e, portanto, nas transformações sociais do mundo. Esse modelo dá crédito total à colaboração e à coletividade e, além disso, à solidariedade e à comunhão enfatizadas em abordagens emancipatórias, como a pedagogia crítica de Freire (por exemplo, FREIRE, 1990), reinstaurando a mensagem política inicial contida, também, na orientação geral de Vygotsky (embora menos pronunciada em trabalhos posteriores dessa escola de investigação devido às pressões do regime top-down [de cima para baixo] que não atribuiu aos indivíduos qualquer papel significativo na criação do seu mundo).

$\mathrm{Na}$ ontologia transformadora, os seres humanos são vistos como agentes ativos de suas próprias vidas e de sua própria sociedade, responsivos e responsáveis - na verdade responsabilizados, nos termos de Bakhtin - agentes que co-criam, junto a outras pessoas, seu mundo e sua sociedade (o termo russo cозидаmesь [literalmente co-criador], com seu prefixo "co-" representando coletividade, transmite esse significado de forma muito direta e vigorosa). Esse retrato desafia as visões dos seres humanos como simplesmente "submetidos" a experiências solitárias (e também a noção de experiência como o principal bloco de construção ontológico), ou como respondentes à química do cérebro e a impulsos e hábitos inconscientes, ou simplesmente como participantes do mundo na conotação de eles simplesmente habitarem e participarem do que já existe no mundo em seu status quo.

A ontologia transformadora da práxis social - aumentada pela noção de contribuições individuais para essa práxis como seus portadores e personificações (como sugerido no posicionamento ativista transformador) - pode ser vista como substituindo a própria distinção entre níveis coletivos e individuais ou dimensões de práticas sociais. O que é oferecido, em vez disso, é um domínio ou processo unitário que precisa de novos termos para transmitir o amálgama dialético do social e do individual - como a "prática coletiva". Esse termo sugere que os indivíduos sempre agem juntos na busca de seus objetivos comuns, sendo inescapavelmente ligados por laços e filamentos comunitários, mas cada indivíduo age a partir de uma posição sócio-histórica única (ponto de vista) e com um compromisso único (desfecho), embora sempre coordenado e alinhado aos projetos/práticas sociais para os quais esse compromisso contribui. Nessa abordagem dialética, não há necessidade de se livrar de um indivíduo porque não existe tal coisa como indivíduo - um ser humano solitário realizando qualquer coisa que se desconecte de outras pessoas e fora das práticas sociais primordiais e seus vínculos. Em vez disso, cada ser humano individual é um conjunto de relações sociais (como Marx afirmou), sendo primeiro formado dentro e fora dessas relações e, em seguida, vindo a incorporar, realizar e expandir essas relações sociais por meio de seus próprios atos. Para apreciar verdadeiramente esse ponto, é necessário um rompimento resoluto com o dualismo do individual e do social, pelo qual cada ser bumano individual é concebido como profunda e profundamente social - isto é, como uma instância da história comum e da humanidade em suas vicissitudes e expressões locais, levando-as adiante e responsabilizando-se pelo seu futuro. Ver a

Práxis Educativa, Ponta Grossa, v. 17, e2219943, p. 1-22, 2022 Disponível em: < https://revistas2.uepg.br/index.php/praxiseducativa> 
história e a sociedade incorporadas e expressas, ou mesmo criadas por meio das ações de cada pessoa - embora em última análise na forma de processos coletivos para os quais essas ações contribuem - é uma tarefa verdadeiramente desafiadora que ainda requer muita atenção e elaboração.

Nessa perspectiva, o desenvolvimento e a aprendizagem são conquistas colaborativas de natureza ativista não limitadas a se adaptar ao que é "dado" no mundo; em vez disso, esses processos dependem de indivíduos formando e realizando suas agendas orientadas para o futuro, que contribuem para projetos colaborativos de transformação social. Essas agendas envolvem centralmente assumir um posicionamento ativista baseado em uma visão, ou "desfecho", de como os membros da comunidade acreditam que as práticas presentes podem ser mudadas e que tipo de futuro deve ser criado. A principal implicação desse conjunto de premissas é que uma pessoa individual - que, para ser, precisa agir no mundo social que está em constante mudança e, além disso, que está mudando por meio de seus próprios atos - não pode ser neutra ou incerta porque tal ação (ao contrário de reagir, habitar passivamente ou participar) pressupõe saber "qual o lado certo" e que direção seguir. Isso coloca a noção de posicionamento ativista face a face com o mundo, consubstanciada em objetivos e compromissos de transformação social, no cerne da ontoepistemologia do desenvolvimento humano. Assim, o ponto mais crítico no posicionamento ativista transformador é que, ao contrário da filosofia moral e de algumas interpretações neomarxistas, os níveis de atividades individuais e coletivas são interligados por meio da verificação de que cada pessoa individual, enquanto é moldada e constituída por práticas e processos materialsemióticos e totalmente dependente de seus recursos e de suas ferramentas, ao mesmo tempo se importa profundamente com tudo o que está acontecendo - com nossas práticas coletivas, nossa história comunitária e com o próprio futuro que está por vir. Não só cada pessoa importa na práxis coletiva, mas a maneira como ela importa é o que constitui o desenvolvimento e permite a formação de uma identidade que, portanto, é ao mesmo tempo inelutavelmente social $e$ profundamente individual. Além disso, de forma paradoxal, as expressões mais profundas e autênticas de individualidade são profundamente sociais e colaborativas - refletidas na noção de missão social de uma pessoa no mundo que marca indivíduos verdadeiramente únicos (por exemplo, ver STETSENKO; ARIEVITCH, 2004).

Nessa premissa, o posicionamento e a tomada de posição ativistas são as dimensões primordiais de desenvolvimento e de aprendizagem, que já estão presentes no nível de processos mesmo presumivelmente "elementares", como percepção e experiência, e ainda mais plenamente expressos em níveis de compreensão conceitual e identidade/pessoalidade. Isso significa que até mesmo atos "simples" da mente humana são determinados por objetivos e compromissos, ou seja, por um esforço ativista que necessariamente envolve ir além do status quo na vida e também, simultaneamente, nas práticas comunitárias. O que está em jogo é a centralidade abrangente do engajamento ativista no e com o mundo, implicando que não há como nos retirarmos desse engajamento. Nunca podemos assumir uma postura neutra de um observador desinteressado e não envolvido com o que está acontecendo no mundo. O último ponto foi expresso de várias maneiras em estudos críticos e feministas (por exemplo, HARDING, 1992; HOWE, 2003; MORAWSKI, 1994). O que o posicionamento ativista transformador acrescenta a isso é que nunca podemos assumir uma postura neutra de um observador desinteressado não envolvido com o que está acontecendo no mundo, porque o que está acontecendo no mundo é um processo no qual nós mesmos estamos diretamente implicados como seus co-criadores, por meio de nossas contribuições ativistas (ainda que em pequena escala e de forma modesta) que sempre importam e, além disso, que constituem o mundo e a nós mesmos. Desse modo, o que é adicionado pelo posicionamento ativista transformador é o fundamento ontológico profundo para legitimar o ponto sobre a parcialidade inelutável do conhecimento derivado de considerações dos princípios dialéticos e condições chave do desenvolvimento humano e social com base na ontologia não dualista.

Práxis Educativa, Ponta Grossa, v. 17, e2219943, p. 1-22, 2022 Disponível em: < https://revistas2.uepg.br/index.php/praxiseducativa $>$ 


\section{Implicações do posicionamento ativista transformador para a subjetividade humana e a noção de futuro}

É sobre uma base sólida de uma visão social e comunitária sobre o desenvolvimento humano como um processo coletivo instanciado por meio de contribuições para práticas sócio-históricas colaborativas que a centralidade da agência pessoal, compromisso e responsabilidade - e de todas as formas de subjetividade humana - pode ser apurada. Porque a práxis comunitária humana atuada por meio de contribuições individuais é conceituada no posicionamento ativista transformador como o domínio ontológico primário e unificado constitutivo, tanto do desenvolvimento humano quanto do mundo (vida) social em que o desenvolvimento ocorre, com ambos co-criados por meio da práxis, essa extensão conceitual abre caminhos para revelar como a subjetividade e a intersubjetividade humanas são encarnações das práticas sociais - sem quaisquer rupturas ou lacunas ontológicas postas entre elas, por um lado, e a práxis social da qual derivam e servem, por outro. $\mathrm{O}$ estabelecimento dessa conexão é possível se atentarmos para a abrangência de como a pessoa atua como sujeito social e também revelarmos a complexidade das formas como as ações dessa pessoa contribuem para as mudanças nas práticas em curso na comunidade e, portanto, para o seu futuro. Essa afirmação permite um conceito não dualista de subjetividade humana que rejeita vê-la como um processo puramente mentalista e contemplativo, como implícito na noção de reflexão e, em vez disso, a considera uma dimensão plenamente legítima de instanciações coletivas e individuais da práxis social.

O que substitui as visões tradicionais é a noção de subjetividade em sua "facticidade" radical (MERLEAU-PONTY, 1962), ou em sua relevância prática - como um processo que está envolvido e implicado em mudanças e transformações nas práticas colaborativas que ocorrem no mundo social, entendido como um fórum das ações humanas. A subjetividade humana então ganha seu status ontológico por meio de seu papel e lugar nas transformações sociais em curso - como contingente de e determinado por como ela importa nos domínios mais amplos da vida social comunitária e suas transformações em curso. A relevância prática da subjetividade humana pode ser verificada pelo devido reconhecimento da materialidade das práticas sociais humanas e seus atos constitutivos - conforme estabelecido precisamente à luz das mudanças incessantes e permanentes em que incorrem (como sempre fazem) no mundo que se desdobra como o fluxo de práticas sociais e em que as pessoas e seu mundo são interanimados.

Em outras palavras, os fenômenos da subjetividade humana se revelam em sua relevância prática, ou seja, em seu papel e sua "significância" na totalidade da vida individual, que, por sua vez, é uma faceta das práticas coletivas, isto é, ela mesma dotada de sentido à luz das buscas individuais que permitem (ou às vezes não permitem) contribuir para essas práticas e formas de vida comunitária. Uma advertência importante é que os indivíduos nem sempre podem estar cientes de como exatamente suas atividades contribuem para o mundo, ou podem estar em uma busca constante por tais atividades, lutando para dar sentido às suas vidas e encontrar "seu caminho". No entanto, apesar da falta de consciência e de luta, muitas vezes contínua para encontrar um projeto de vida significativo (atividade de liderança), as pessoas sempre contribuem sim para algo que acontece no mundo. Isso é verdade mesmo que essas contribuições sejam apenas em pequena escala, e mesmo que sejam trazidas pela abstenção de contribuições ativistas para esses processos - porque o último tipo de "contribuição" muitas vezes funciona para perpetuar o status quo existente, para sufocar mudanças na sociedade e, portanto, também faz a diferença, embora na forma de uma negatividade. Portanto, em última análise, o que leva a pessoa a ser posicionada por suas atividades para mudar o mundo e a si mesma como parte do mundo - para que objetivo e para que tipo de futuro uma pessoa contribui - é a questão central, cuja resposta é necessária na análise da subjetividade humana que rompe com o dualismo cartesiano, e quebra-o.

Práxis Educativa, Ponta Grossa, v. 17, e2219943, p. 1-22, 2022 
O tipo de ontoepistemologia baseada em ações ativistas que contribuem para as práticas sociais e representam o futuro significa que a direção de nossas ações (unificadas como um projeto de vida contínuo) é central para formar conceitos. Essa direção é formada por objetivos e compromissos com o futuro assumidos por meio de contribuições a projetos colaborativos de transformação social, pela postura que assumimos perante o mundo e pelo caminho que traçamos para chegar ao nosso destino. De outro modo, o que o posicionamento ativista transformador destaca é o posicionamento ativista, voltado para o futuro e, portanto, o futuro, o borizonte e o destino do desenvolvimento e da pessoalidade. Essa dimensão foi subteorizada pela teoria históricocultural, cujo foco principal foi colocado na história e, assim, no passado, com a exclusão de questões sobre como o futuro, concebido em termos ativistas como uma visão com a qual os indivíduos se comprometem, desempenha um papel formativo no desenvolvimento.

A noção de posicionamento ativista guarda alguma semelhança, mas não é idêntica à noção de prolepse como uma "[...] característica onipresente do pensamento culturalmente mediado" (COLE, 1996, p. 183) que chama atenção para "[...] a representação de um ato futuro ou desenvolvimento como sendo atualmente existente" (COLE, 1996, p. 183). O que o posicionamento ativista transformador acentua é que, em vez de focar na representação do futuro como sendo atualmente existente (um conceito com conotações inevitavelmente mentalistas), a atuação humana é contingente em indivíduos se comprometendo com uma determinada versão do futuro e, o mais importante, "sempre já" criando gradualmente esse futuro por meio de ações no presente. Isso permite uma ligação mais direta de atuação no presente para como os indivíduos atuam (enact) o mundo em que desejam viver, e o que eles tomam como um "dever" para os futuros projetados de práticas comunitárias - quebrando, assim, a barreira absoluta entre o presente e o futuro e destacando a construção do futuro em e por meio das atividades e das ações atualmente em andamento.

Desse modo, a prolepse (antecipação, previsão) é semelhante a uma expectativa de que um certo futuro é iminente ou provável e, portanto, semelhante à noção de endereçamento de Bakhtin - agindo com uma expectativa de resposta ao enunciado de alguém nas obras de Bakhtin (1990, por exemplo) ou à ação de alguém em uma posição mais ampla, como a prolepse. Nessa abordagem, a resposta futura, embora apenas antecipada, medeia a produção dos enunciados e das ações já no presente. A diferença com o posicionamento ativista transformador, porém, é que, enquanto tanto a prolepse quanto o endereçamento se baseiam na noção de que o futuro é imaginado e antecipado, enquanto a pessoa atua como se esse futuro já existisse, a noção de atos humanos baseados em um compromisso com o futuro - como algo que deveria ser - é mais agentiva e intencional. O que a noção de compromisso sugere é que uma pessoa não tanto espera ou antecipa o futuro, mas, sim, trabalha ativamente para trazer esse futuro à realidade por meio de seus próprios atos, muitas vezes contra todas as probabilidades, isto é, mesmo se uma versão particular do que virá no futuro não é prevista como provável e, em vez disso, requer luta e esforço para alcançá-la. Isso se aplica nos casos em que uma pessoa luta por uma visão de "o que deveria ser", apesar das forças poderosas que podem estar puxando para outras direções. Nesse sentido, a noção de compromisso central para o posicionamento ativista transformador está mais próxima da noção de Nikolai N. Bernstein (1966, por exemplo) de "o futuro requisitado" ou (o que eu acredito ser uma tradução melhor) "futuro almejado", em vez das noções de prolepsis e endereçamento.

Bernstein (e trabalhos relacionados por P. K. Anokhin) postulou que os organismos baseiam sua atividade não apenas em respostas ao que existe no "aqui e agora", mas no que uma pessoa está antecipando e prevendo irá, e também projetando o que deveria, existir no futuro. Nas palavras de Bernstein (1966):

Temos, ao que tudo indica, dois processos conectados. Um deles é a previsão probabilística de acordo com a situação atual percebida [semelhante à prolepse]. [...]. Paralelamente a essa extrapolação probabilística do curso dos eventos circundantes [...] há o processo de

Práxis Educativa, Ponta Grossa, v. 17, e2219943, p. 1-22, 2022 Disponível em: < https:// revistas2.uepg.br/index.php/praxiseducativa $>$ 
programação do ato que deve levar à realização do futuro almejado [ou necessário, requerido]. (BERNSTEIN, 1966, p. 438, tradução nossa).

O último processo de buscar o futuro e agir com base no que deve ser e no que é procurado pode ser entendido como uma luta contínua para atingir os próprios objetivos na realização de atividades direcionadas a um objetivo. Estendendo essa noção para capturar o que é único sobre os humanos agindo como sujeitos sociais, como "coletividual' (em vez de quais são as características de todos os organismos vivos, como nas obras de Bernstein e Anokhin), a seguinte especificação pode ser feita. O "futuro almejado" é assumir o que se aspira alcançar no presente, agindo na premissa do que deve ser criado - atuado e inventado no presente como uma realização do futuro que está por vir. Nessa ênfase, a noção de compromisso com o futuro acentua não tanto que futuro é trazido ao presente por meio da imaginação ou da representação, como na prolepse, mas que futuro é criado e inventado no presente. A principal distinção é precisamente entre a expectativa de que algo vai acontecer ou é provável que aconteça no futuro, enquanto se prepara para isso, versus um compromisso com um futuro que uma pessoa acredita que "deveria" acontecer e, portanto, atua para realizar no futuro nos esforços para torná-lo realidade agora, inventando ativamente o futuro - em vez de simplesmente se preparar para ele. Essa conceituação é derivada dela mesma e apóia a mensagem geral central para o posicionamento ativista transformador - sobre o desenvolvimento e a aprendizagem como projetos ativistas de devir histórico na intersecção de processos individuais e coletivos na zona de desenvolvimento proximal, entendida como o que está sendo criado agora no forma de uma realização do futuro no presente.

\section{Implicações do posicionamento ativista transformador para a subjetividade humana: conceitos como um processo de coautoria}

\section{Práticas da comunidade}

No relato apresentado nas seções anteriores, a subjetividade humana não é um módulo independente ou um dispositivo a serviço de objetivos separados e distintos dos indivíduos, como a compreensão cognitiva, desconectada da totalidade da vida individual que ela mesma está de alguma forma desconectada dos processos e das práticas sociais e coletivas. Em vez disso, a subjetividade é posta como apenas uma dimensão na realização da totalidade da vida de cada ator social, ou de seus projetos de vida - como um pisante na realização de um caminho unitário e único (embora dinâmico e em constante mudança), contínuo e incessante (embora não sem contradições) de se tornar um ser humano ao fazer a diferença no mundo (ver STETSENKO, 2010a). Dentro dessa ontologia "coletividual" e transformadora geral, a subjetividade humana pode ser considerada como uma parte, ou uma dimensão, da realização do projeto de vida - um caminho de ações significativas e responsáveis que trazem à tona o mundo comunitário por meio de nossa atuação, de quem nós queremos ser e o que queremos que o nosso mundo seja.

Uma das implicações é que, nesse sentido, o desenvolvimento do conhecimento é também, e simultaneamente, o desenvolvimento da identidade e do eu. Os fortes laços e as conexões entre aprendizagem e identidade têm sido destacados nos estudos socioculturais, sugerindo que a aprendizagem envolve a construção de identidades - em que a aprendizagem cria identidade, e a identidade cria aprendizagem (por exemplo, LAVE; WENGER, 1991; NASIR; SAXE, 2003; WENGER, 1998; PACKER; GOECOECHEA, 2000). Além disso, ao expandir essas ideias, vários pesquisadores têm notado que a participação nas práticas da comunidade não é isenta de tensões e de custos (por exemplo, HODGES, 1998; LINEHAN; MCCARTHY, 2001; PACKER; GOECOECHEA, 2000) e que a participação não deve ser reduzida a um processo de cumprimento

Práxis Educativa, Ponta Grossa, v. 17, e2219943, p. 1-22, 2022 
da normatividade das regras e das funções da comunidade. Essa linha de pesquisa se sobrepõe, em certa medida, a uma crítica mais ampla do excesso de confiança na pesquisa sociocultural sobre os processos de internalização e de apropriação em detrimento da compreensão da agência dos próprios participantes que desafia e resiste às práticas da comunidade (ENGESTRÖM, 1999; HOLLAND et al., 1998; STETSENKO; ARIEVITCH, 2004b; VIANNA; STETSENKO, 2011).

Por exemplo, Packer e Goicoechea (2000) fizeram uma série de sugestões úteis sobre os fundamentos ontológicos e epistemológicos das teorias socioculturais e construtivistas. A proposta resultante é para a ontologia não dualista, a qual pode ser revelada como "[...] a noção de aprendizagem da perspectiva sociocultural - ganhar conhecimento ou compreensão - é parte integrante de mudanças ontológicas mais amplas que decorrem da participação em uma comunidade" (PACKER; GOICOECHEA, 2000, p. 234). Nessa linha, esses autores afirmam que "[....] aprender envolve tornar-se membro de uma comunidade, construir conhecimentos em vários níveis de expertise como participante, mas também posicionar-se sobre a cultura de sua comunidade no esforço de assumir e superar o distanciamento e a divisão que são consequências da participação" (PACKER; GOICOECHEA, 2000, p. 227, grifo nosso). Nesse relato, no entanto, em que os aprendizes se posicionam, refere-se principalmente a como os membros da comunidade os posicionaram e como estão tentando superar a alienação. Assim, o processo ontológico central envolvido na identidade e na aprendizagem é retratado como o esforço dos aprendizes para chegar a um acordo sobre como as práticas da comunidade os posicionam e, então, diz respeito à maioria de todos os enigmas individuais, interesses próprios e sentimentos decorrentes das experiências individuais de participação, incluindo seus aspectos negativos, como alienação, em vez de uma posição sobre a dinâmica geral e política da comunidade como uma instituição social. Dessa maneira, a noção de "assumir uma posição" é entendida de forma diferente. Por conseguinte, embora esses autores reconheçam que "[...] aprender implica a transformação tanto da pessoa quanto do mundo social" (PACKER; GOICOECHEA, 2000, p. 227), uma transformação ativista do que se passa nas práticas comunitárias ao longo das linhas do compromisso com o futuro não é considerada como o núcleo, a dimensão ontológica direta da aprendizagem e da identidade. Assim, a ontologia discutida em Packer e Goicoechea (2000) é principalmente a ontologia dos indivíduos como pessoas (ou seja, na consideração do que significa para alguém ser), especialmente quando participam de comunidades.

A especificação crítica para essas linhas de pesquisa oferecidas pelo posicionamento ativista transformador e sua ontoepistemologia das contribuições individuais para as práticas sociais como uma práxis social unificada é que o núcleo da identidade e da aprendizagem está diretamente conectado aos aprendizes assumirem uma posição como atores sociais, sobre como suas comunidades enquanto instituições sociais precisam e devem ser mudadas para melhor (não apenas uma posição em como as comunidades os posicionam) - imaginando o futuro pelo qual vale a pena lutar e assumindo o compromisso de realizar essas mudanças. Assim, a aprendizagem e a identidade são vistas como co-extensivas, e só possíveis por meio do mapeamento de uma agenda de vida baseada em uma visão de mudança social para a comunidade, atuada por meio da prática transformativa colaborativa e sua própria contribuição para com ela (para detalhes e ilustrações empíricas, ver VIANNA; STETSENKO, 2011). Nesse sentido, o posicionamento ativista transformador é semelhante ao modelo de ação dialógica da democracia crítica (JARAMILLO, 2011), traçando suas raízes no quadro crítico marxista-freiriano que começa com a compreensão de que a existência humana depende do "[...] direito e do dever de optar, por decidir, por lutar, por ser político" (FREIRE, 2001, p. 53).

Em outras palavras, a partir do posicionamento ativista transformador, o processo-chave na interface de aprendizagem e de identidade tem a ver com nosso envolvimento ativo com eventos e práticas, circunstâncias e enigmas, contradições e dilemas de práticas sociais das quais

Práxis Educativa, Ponta Grossa, v. 17, e2219943, p. 1-22, 2022 Disponível em: < https:// revistas2.uepg.br/index.php/praxiseducativa $>$ 
participamos - e, além disso, com esses compromissos em suas contingências em nosso interesse pessoal, reivindicamos e nossa posição ativista que assumimos na dinâmica geral e no drama social dessas práticas. No entanto, esses interesses e essas posições pessoais nunca são "apenas" pessoais - em vez disso, a aprendizagem e o desenvolvimento se unem quando, na verdade, nos afastamos das preocupações apenas com "nós mesmos", apenas sobre como somos individualmente posicionados, tratados etc. - como se fôssemos independentes dos outros, o que obviamente é uma ilusão. A aposta significativa nos eventos, então, é sobre um processo ativo - na verdade, ativista - de se tornar o que é atuado por meio de nossas ações passadas, presentes e futuras que criam o mundo em que vivemos juntos. Assim, a aprendizagem torna-se verdadeira e pessoalmente significativa quando é colocada a serviço de dar sentido a "quem eu sou" e "quem eu quero me tornar" - com esses processos sendo contingentes e somente possíveis por meio de descobrir $o$ que eu quero que meu mundo venha a ser.

Tudo isso implica que os seres humanos - já em virtude de serem humanos - sempre agem e sabem de formas que são significativas e que importam em suas agendas de vida em evolução e visões de futuro ligadas à dinâmica social e política de nossas comunidades. Ou seja, o desenvolvimento é possível com base em pessoas agindo como ativistas que não podem, nem devem tentar evitar agir e saber a partir de seus posicionamentos ativistas, com visões e compromissos (e emoções, sentimentos e paixões associadas) criticamente incorporados em cada ato de conhecimento, incluindo todo ato de compreensão conceitual. Esperar ou exigir que as pessoas façam o contrário, por exemplo, que entendam as coisas apenas intelectualmente, de uma forma desapaixonada, imparcial ou de alguma forma "objetiva", equivale a nada menos do que desumanização. Infelizmente, muitas forças sociais poderosas, incluindo a educação formal em suas formas existentes, agem exatamente de maneiras que desumanizam os aprendizes e tiram seu ativismo - priorizando o cumprimento e a adaptação ao status quo, restringindo espaços para engajamento ativista e negando as ferramentas necessárias para desenvolvê-lo e exercitá-lo. Nesses modelos e formas educacionais dominantes, a aprendizagem e o conhecimento são transformados em um exercício semelhante a uma máquina de lançar fatos que não têm significado humano, nem relevância e importância prática, impedindo, assim, o desenvolvimento tanto dos indivíduos quanto da sociedade.

Voltando aos debates atuais sobre a TAHC, a posição delineada neste artigo ajuda a iluminar o papel da subjetividade humana como não redutível ao de meramente refletir o mundo. Para usar o exemplo do trabalho de Lektrosky (2009) novamente, sua visão sobre a noção de reflexão é capturada na ilustração a seguir. Em suas palavras, "[...] a reflexão como um ato da consciência individual não muda necessariamente seu objeto" (LEKTROSKY, 2009, p. 86). Isso contradiz uma velha conotação de que a reflexão é de alguma forma separada da atividade incorporada no projeto geral de se tornar compreendido como uma parte integrante da práxis comunitária que sempre muda seu objeto. Como Lektorsky ainda afirma, "[...] por exemplo, quando os indivíduos refletem sobre sua personalidade e, como resultado, não gostam de si mesmos, isso muda algo neles. Pode surgir algo como uma crise de identidade. Mas isso não significa necessariamente que a personalidade mude" (LEKTROSKY, 2009, p. 86). Nesse exemplo, Lektorsky não tão tacitamente transforma a reflexão em um processo que é de alguma forma separado e até mesmo anterior, bem como inconsequente para um engajamento transformativo ativo com o mundo (incluindo a si mesmo como seu participante). Esse processo de reflexão, segundo Lektorsky, pode, às vezes, resultar em mudanças e, às vezes, não ter efeitos transformadores. Da perspectiva do posicionamento ativista transformador, no entanto, "reflexão" (se esse termo deve ter alguma valor) deve ser concebida como apenas uma faceta de um envolvimento transformador que só acontece se e na medida em que tal envolvimento inevitavelmente sempre transformador tanto da pessoa quanto do mundo social - já ocorre. "Refletir

Práxis Educativa, Ponta Grossa, v. 17, e2219943, p. 1-22, 2022 Disponível em: < https://revistas2.uepg.br/index.php/praxiseducativa> 
sobre a própria personalidade" e estar insatisfeito consigo mesmo não muda apenas necessariamente a pessoa, como de fato sempre muda; mais importante, empreender tal "reflexão" precisa ser reconstruído longe das conotações de espelhar "o que é" e, em vez disso, proporcionam uma dimensão inerente de fazer algo no mundo, como um ato que importa e faz a diferença. Nesse exemplo, estar insatisfeito consigo mesmo significa sim que a pessoa já embarcou em um projeto transformador - porque é precisamente da posição de uma pessoa mudada, ou pelo menos uma pessoa que está lutando para mudar, que o eu atual pode ser visto, refletido e criticado (e considerado deficiente em alguns aspectos). Uma reflexão crítica só é possível a partir de uma trajetória de mudança de envolvimento no mundo como um ator social - não como uma "reflexão" mental separada. Como sugerido aqui, a reflexão crítica e o conhecimento crítico são formas de atividade transformadora crítica no mundo, possível quando os elementos de um novo caminho de atividade já foram criados, ainda que apenas em uma forma nascente. Essa posição está de acordo com a lógica marxista expressa na afirmação profundamente dialética de que quando "[...] as pessoas falam de ideias que revolucionam a sociedade, elas apenas expressam o fato de que, dentro da velha sociedade, os elementos de uma nova tenha sido criado [...]" (MARX; ENGELS, 1978, p. 489).

\section{Conclusões: implicações para a Educação}

Em vez de conclusões, é útil ilustrar aplicações práticas que podem ser derivadas do relato apresentado nas seções anteriores. Estes dizem respeito especialmente aos princípios de ensino e de aprendizagem. Na abordagem de Davydov (1988, por exemplo), uma vez que foi amplamente implementada no desenvolvimento de currículos e de práticas educacionais, a estratégia estava totalmente alinhada à teoria "canônica" (cf. SAWCHUK; STETSENKO, 2008) do desenvolvimento humano, incluindo seus pressupostos sobre a natureza da subjetividade humana. Partindo da conjectura de que a subjetividade humana tem a ver com a aquisição de experiências socioculturais da humanidade desenvolvidas ao longo da história das práticas humanas, a estratégia foi imergir os alunos nas práticas socioculturais oriundas do passado e também introduzir os alunos aos conhecimentos como ferramentas culturais para resolver os problemas encontrados nessas práticas. Assim, o conhecimento e suas personificações diversificadas em conceitos foram introduzidos como ferramentas práticas e valiosas derivadas e aplicáveis dentro de práticas socioculturais particulares, com significado de conceitos inerentemente vinculados à sua aplicabilidade e relevância prática historicamente desenvolvida nessas práticas (para detalhes, ver ARIEVITCH; STETSENKO, 2000). Essa estratégia notável permitiu preencher com eficiência a lacuna entre a prática e a teoria - tornar os conceitos significativos por meio da revelação de práticas e histórias "escondidas" por trás deles mostrou ser a maneira de tornar os conceitos tangíveis e práticos ao mesmo tempo e, precisamente por intermédio dessa estratégia, eles também são verdadeiramente teóricos. Esse tipo de ensino-aprendizagem foi mostrado para permitir que os alunos apreendam os conceitos teóricos, muitas vezes aparentemente abstratos, de formas totalmente práticas, ou seja, adquirindo esses conceitos aparente e "meramente" teóricos como guias práticos de fato para a ação. Essa metodologia seguiu o princípio fundamental de que é por meio da compreensão de como os conceitos "passam a existir" na história, como ferramentas das práticas sociais, que esses conceitos podem ser apreendidos simultaneamente em termos de como podem ser postos para funcionar na prática e, precisamente por intermédio disso, teoricamente entendidos. A teoria, portanto, era vista não como uma forma separada de saber que estava desconectada da prática, mas como uma forma de prática que encapsula (de forma generalizada e abreviada) as formas de agir mais eficientes e historicamente relevantes. Além disso, uma estratégia de ensino relacionada envolveu a introdução de conhecimento aos alunos não apenas como uma ferramenta que emerge e faz sentido dentro das práticas passadas, mas como em si mesma, incorporando a atividade e representando modelos abreviados para a prática que precisa ser

Práxis Educativa, Ponta Grossa, v. 17, e2219943, p. 1-22, 2022 Disponível em: < https:// revistas2.uepg.br/index.php/praxiseducativa $>$ 
aprendida por meio da atuação no presente (como no princípio de "aprender fazendo", também empregado nas abordagens construtivistas). Por exemplo, o conceito de número foi introduzido como um modelo para a realização de atividades práticas de medição que surgiram na história da civilização e que os alunos precisam se envolver ativamente e replicar na realização de suas próprias atividades no presente.

Uma maneira de expandir ainda mais esta conceptualização do posicionamento ativista transformador é considerar os conceitos em sua relevância não apenas dentro do passado histórico e do presente contínuo, por meio do qual os alunos são introduzidos em práticas que replicam o legado histórico "por trás" dos conceitos e instruídos como realizar essas práticas no "aqui e agora" (ver STETSENKO, 2010b). Além disso - não em vez disso! - os alunos devem empregar o conhecimento em sua relevância para as atividades futuras que eles buscam, visto que estas são visualizadas pelos próprios alunos em sua formação gradativa de buscas significativas de seus próprios objetivos e visões para o futuro, do que deveria ser. A partir do posicionamento ativista transformador, os conceitos, como todas as ferramentas culturais também, precisam ser ativamente aproveitados e reinventados pelos aprendizes, em vez de adquiridos ou replicados e, portanto, ser autores à luz da formação de seu próprio caminho $e$ de seus próprios projetos de vida nascentes, visto que são voltados para o futuro, mas sempre já lançados no presente. Nesse caso, a aprendizagem e o desenvolvimento são destacados como relacionados não apenas à posição de alguém nas práticas da comunidade em seu passado e presente, mas, ao mesmo tempo, e centralmente, a um compromisso de mudar essas práticas por meio de suas próprias (individuais, mas não a-sociais ) perseguições direcionadas a objetivos. Ou seja, a estratégia é tornar os conceitos significativos, transformando-os nas ferramentas dos aprendizes, formando suas atividades e agendas de vida (ou projetos de vida), em que tanto os conceitos quanto os projetos de vida começam a se aglutinar e a coevoluir.

Em outras palavras, o ensino-aprendizagem deve ser organizado de forma que o conhecimento seja revelado: (a) como decorrente da prática social - como suas ferramentas constituintes; (b) por meio da prática social - em que as ferramentas são redescobertas por meio de explorações e de pesquisas ativas dos alunos; e (c) para a prática social - em que o conhecimento é tornado significativo à luz de sua relevância dentro de atividades substanciais para os alunos, isto é, em que os conceitos são transformados em ferramentas de seu próprio desenvolvimento e de sua própria identidade emergente como sujeitos sociais que importam no desdobramento dinâmico das práticas colaborativas. Essa posição representa uma extensão da abordagem vygotskiana de ensinoaprendizagem, adicionando ênfase na necessidade de estabelecer relevância mútua entre as identidades dos alunos e seus conhecimentos, que dizer, estabelecer interdependências entre conceitos e agendas de vida emergentes dos alunos como um contexto no qual esses conceitos são aplicáveis de maneiras verdadeiramente "personalizadas" - isto é, profundamente sociais - e, portanto, profundamente significativas. É dentro desse contexto que o evento de compreensão é exclusivamente possível - como o ato de criar o futuro na interseção da agência individual e coletiva nas zonas sempre crescentes e mutáveis do desenvolvimento proximal.

Para resumir a posição-chave promovida neste artigo, o repúdio resoluto ao dualismo cartesiano e sua noção de indivíduos isolados fora das coletividades, dotados de mentes solipsistas que desfilam conceitos e processam informações dentro do domínio isolado do cérebro ou nas "profundezas mentais", pode ser alcançado ao recuperar e reivindicar indivíduos como atores sociais - cocriadores de práticas das comunidades e nossa história comum; e a subjetividade individual como um processo totalmente social, corporificado, material-discursivo que ganha seu status ao contribuir para as práticas sociais e ao desempenhar um papel nelas (tomando emprestado o termo de Barad, 2007,

Práxis Educativa, Ponta Grossa, v. 17, e2219943, p. 1-22, 2022 Disponível em: < https://revistas2.uepg.br/index.php/praxiseducativa> 
mattering ${ }^{2}$ in them), tornando-se, assim, real. Esse objetivo só pode ser alcançado com base em uma reconstrução radical das premissas fundamentais sobre não apenas camadas individuais e coletivas de práticas sociais, mas a ontologia e a epistemologia básicas dessas práticas como o núcleo do desenvolvimento humano, da dinâmica social e da própria realidade. Os passos em direção a tal reinterpretação transformadora, longe das noções de adaptações, é o que se busca no posicionamento ativista transformador, em linha com o espírito central dessa abordagem que sugere constante renovação, inovação e movimento para além do dado.

\section{Referências}

ARIEVITCH, I. M.; STETSENKO, A. The quality of cultural tools and cognitive development: Gal'perin's perspective and its implications. Human Development, v. 43, n. 2, p. 69-92, mar./abr. 2000. DOI: https://doi.org/10.1159/000022661

BAKHTIN, M. M. Art and answerability: early philosophical essays by M. M. Bakhtin. Austin: University of Texas Press, 1990.

BAKHTIN, M. M. Toward a philosophy of the act. Austin: University of Texas Press, 1993.

BAKHURST D.; PADDEN, C. The Meshcheryakov experiment: Soviet work on the education of blind-deaf children. Learning and Instruction, v. 1, n. 3, p. 201-215, jan. 1991. DOI: https://doi.org/10.1016/0959-4752(91)90003-q

BARAD, K. Meeting the universe halfway: quantum physics and the entanglement of matter and meaning. Durham: Duke University Press, 2007.

BERNSTEIN, N. N. Essays on the physiology of movement and physiology of activity. Moscow: Nauka Press, 1966.

CLARK, A. Being there: Putting brain, body, and world together again. Cambridge, MA: MIT Press, 1997.

COLE, M. Cultural psychology: A once and future discipline. Cambridge, MA: Harvard University Press, 1996.

DAVYDOV, V. V. Problems of developmental teaching. Soviet Education, v. 30, n. 9, p. 3-83, 1988. DOI: https://doi.org/10.2753/RES1060-939330086

DAVYDOV, V. V. The influence of L. S. Vygotsky on education theory, research, and practice. Educational Researcher, v. 24 n. 3, p. 12-21, 1995. DOI: https://doi.org/10.3102/0013189x024003012

ENGESTRÖM, Y. Activity theory and individual and social transformation. In: BROWN, J, S. et al. (ed.). Perspectives on activity theory. Cambridge: Cambridge University Press, 1999. p. 1938 .

\footnotetext{
2 Nota de tradução: O termo mattering é de difícil tradução, mas ele conota duas coisas ao mesmo tempo: "fazer a diferença" e "ser de matéria". O último, ser de matéria, conota que se trata de um processo material mundano. Então, aqui, ao dizer que nossa subjetividade surge por meio do mattering, significa que nós e nossa subjetividade nos tornamos reais por intermédio de nosso papel e de nossa contribuição para os processos materiais mundanos.
} 
FREIRE, P. Pedagogy of the oppressed. New York: Continuum, 1990.

FREIRE, P. Pedagogy of freedom. New York: Rowman and Littlefield, 2001.

HARDING, S. Rethinking standpoint epistemology: What is "strong objectivity?" In: ALCOFF, L.; POTTER, E. (ed.). Feminist Epistemologies. New York: Routledge, 1992. p. 49-82.

HODGES, D. C. Participation as dis-identification with/in a community of practice. Mind, Culture, and Activity, Abingdon, v. 5, n. 4, p. 272-290, out. 1998. DOI: https://doi.org/10.1207/s15327884mca0504 3

HOLLAND, D. et al. Identity and agency in cultural worlds. New York: Cambridge University, 1998.

HOWE, K. R. Closing methodological divides: Toward democratic educational research. Boston: Kluwer Academic, 2003.

JARAMILlO, N. Dialogic action for critical democracy. Journal for Critical Education Policy Studies, v. 9, n. 1, p. 72-94, 2011.

LANGEMEYER, I. Contradictions in expansive learning: Towards a critical analysis of selfdependent forms of learning in relation to contemporary socio-technological change. Forum: Qualitative Social Research, v. 7, n. 1, p. 1-17, 2006. DOI: https://doi.org/10.17169/fqs-7.1.76

LAVE, J.; WENGER, E. Situated learning: Legitimate peripheral participation. New York, Cambridge University Press, 1991.

LEKTORSKY, V. A. Mediation as a means of collective activity. In: SANNINO, A.; DANIELS, H.; GUTIERREZ, K. D. (ed.). Learning and expanding with activity theory. Cambridge: Cambridge University Press. 2009. p. 75-87.

LINEHAN, C.; MCCARTHY, J. Reviewing the "community of practice" metaphor: an analysis of control relations in a primary school classroom. Mind, Culture, and Activity, v. 8. n. 2, p. 129147, maio 2001.

MARKOVÁ, I. Objectification in common sense thinking. Mind, culture, and activity, v. 19, p. 207-221, 2012. DOI: https://doi.org/10.1080/10749039.2012.688178

MARX, K.; ENGELS, F. Manifesto of the communist party. In: TUCKER, R. C. (org.). The Marx-Engels reader. 2. ed. New York: W.W. Norton, p. 469-500. 1978.

MERLEAU-PONTY, M. Phenomenology of perception. Translation C. Smith. London: Kegan Paul, 1962.

MORAWSKI, J. G. Practicing feminisms, reconstructing psychology: notes on a liminal science. Ann Arbor: University of Michigan Press, 1994.

NASIR, N. S.; SAXE G. B. Ethnic and academic identities: A cultural practice perspective on emerging tensions and their management in the lives of minority students. Educational Researcher, v. 32, n. 5, p. 14-18, jun. 2003. DOI: https://doi.org/10.3102/0013189x032005014

PACKER, M. J.; GOICOECHEA, J. Sociocultural and constructivist theories of learning: Ontology, not just epistemology. Educational Psychologist, v. 35, n. 4, p. 227-241, dez. 2000. DOI: https://doi.org/10.1207/s15326985ep3504 02 
SAWCHUK, P.; STETSENKO, A. Sociology for a non-canonical activity theory: Exploring intersections and complementarities. Mind, Culture and Activity, v. 15, n. 4, p. 339-360, 2008. DOI: $\underline{\text { https://doi.org/10.1080/10749030802391427 }}$

STETSENKO, A. The role of the principle of object-relatedness in the theory of activity. Journal of Russian \& East European Psychology, v. 33, n. 6, p. $54-69$ nov./dez. 1995. DOI: https://doi.org/10.2753/RPO1061-0405330654

STETSENKO, A. Introduction to "Tool and sign" by Lev Vygotsky. In: RIEBER R. W.; ROBBINSON D. (ed.). Essential Vygotsky. New York: Kluwer/ Plenum. 2004. p. 499-510.

STETSENKO, A. Activity as object-related: Resolving the dichotomy of individual and collective types of activity. Mind, culture, and activity, v. 12, p. 70-88, 2005. DOI: https://doi.org/10.1207/s15327884mca1201 6

STETSENKO, A. Being-through-doing: Bakhtin and Vygotsky in dialogue. Cultural Studies of Science Education, v. 2, n. 4, p. 25-37, 2007.

STETSENKO, A. From relational ontology to transformative activist stance: Expanding Vygotsky's (CHAT) project. Cultural Studies of Science Education, v. 3, p. 471-491, 2008. DOI: https://doi.org/10.1007/s11422-008-9111-3

STETSENKO, A. Standing on the shoulders of giants: A balancing act of dialectically theorizing conceptual understanding on the grounds of Vygotsky's project. In: WOLF, M. R. (ed.). $\mathrm{Re} /$ structuring science education: ReUniting Psychological and Sociological Perspectives, Springer: Dordrecht, 2010a. p. 53-72.

STETSENKO, A. Teaching-learning and development as activist projects of historical Becoming: Expanding Vygotsky's approach to pedagogy. Pedagogies: an International Journal, v. 5, n. 1, p. 6-16, 2010b. DOI: https://doi.org/10.1080/15544800903406266

STETSENKO, A. Darwin and Vygotsky on development: an exegesis on human nature. In: KONTOPODIS, M. et al. (ed.). Children, culture and education. Springer: Dordrecht, 2011. p. $25-41$.

STETSENKO, A. Personhood: an activist project of historical becoming through collaborative pursuits of social transformation. New ideas in Psychology, v. 30, n. 1, p. 144-153, 2012. DOI: https://doi.org/10.1016/i.newideapsych.2009.11.008

STETSENKO, A. Theorizing personhood for the world in transition and change: Reflections from a transformative activist stance. In: MARTIN, J.; BICKHARD, M. H. (ed.). The Psychology of personhood. Cambridge: Cambridge University, 2013. p. 181-202.

STETSENKO, A.; ARIEVITCH, I. M. Vygotskian collaborative project of social transformation: History, politics, and practice in knowledge construction. The International Journal of Critical Psychology, v. 12, n. 4, p. 58-80, 2004a.

STETSENKO, A.; ARIEVITCH, I. The self in cultural-historical activity theory: Reclaiming the unity of social and individual dimensions of human development. Theory \& Psychology, v. 14, n. 4, p. 475-503, ago. 2004b. DOI: https://doi.org/10.1177/0959354304044921

VIANNA, E.; STETSENKO, A. Connecting learning and identity development through a transformative activist stance: application in adolescent development in a child welfare program. Human Development, v. 54, n. 5, p. 313-338, 2011. DOI: https://doi.org/10.1159/000331484 
VYGOTSKY, L. S. The history of the development of higher mental functions. In: RIEBER, R. W. (ed.). The collected works of L. S. Vygotsky. New York: Plenum Press, 1997. v. 4. p. 1-278.

VYGOTSKY, L. S. Pedology of the adolescent. In: RIEBER, R. W. (ed.). The collected works of L.S. Vygotsky. Vol 5: Child psychology. New York: Plenum Press, 1998a. p. 1-184.

VYGOTSKY, L. S. The problem of age. In: RIEBER, R. W. (ed.). The collected works of L.S. Vygotsky. Vol. 5: Child psychology. New York: Plenum Press, 1998b. p. 187-205.

WENGER, E. Communities of practice: learning, meaning, and identity. Cambridge: Cambridge University Press, 1998.

Recebido em 20/09/2020

Aceito em 21/12/2021

Publicado online em 15/01/2022 